\title{
What is the Advantage for Bacteria to Use Polycyclic Aromatic Hydrocarbons as Carbon Source under Aerobic Condition?
}

\author{
Shaomin Yan and Guang $\mathrm{Wu}^{*}$ \\ National Engineering Research Center for Non-Food Biorefinery, State Key Laboratory of Non-Food Biomass and Enzyme \\ Technology, Guangxi Biomass Engineering Technology Research Center, Guangxi Key Laboratory of Bio-refinery, Guangxi \\ Academy of Sciences, China
}

*Corresponding author: Guang Wu, National Engineering Research Center for Non-Food Biorefinery, State Key Laboratory of Non-Food Biomass and Enzyme Technology, Guangxi Biomass Engineering Technology Research Center, Guangxi Key Laboratory of Bio-refinery, Guangxi Academy of Sciences, 98 Daling Road, Nanning, 530007, China

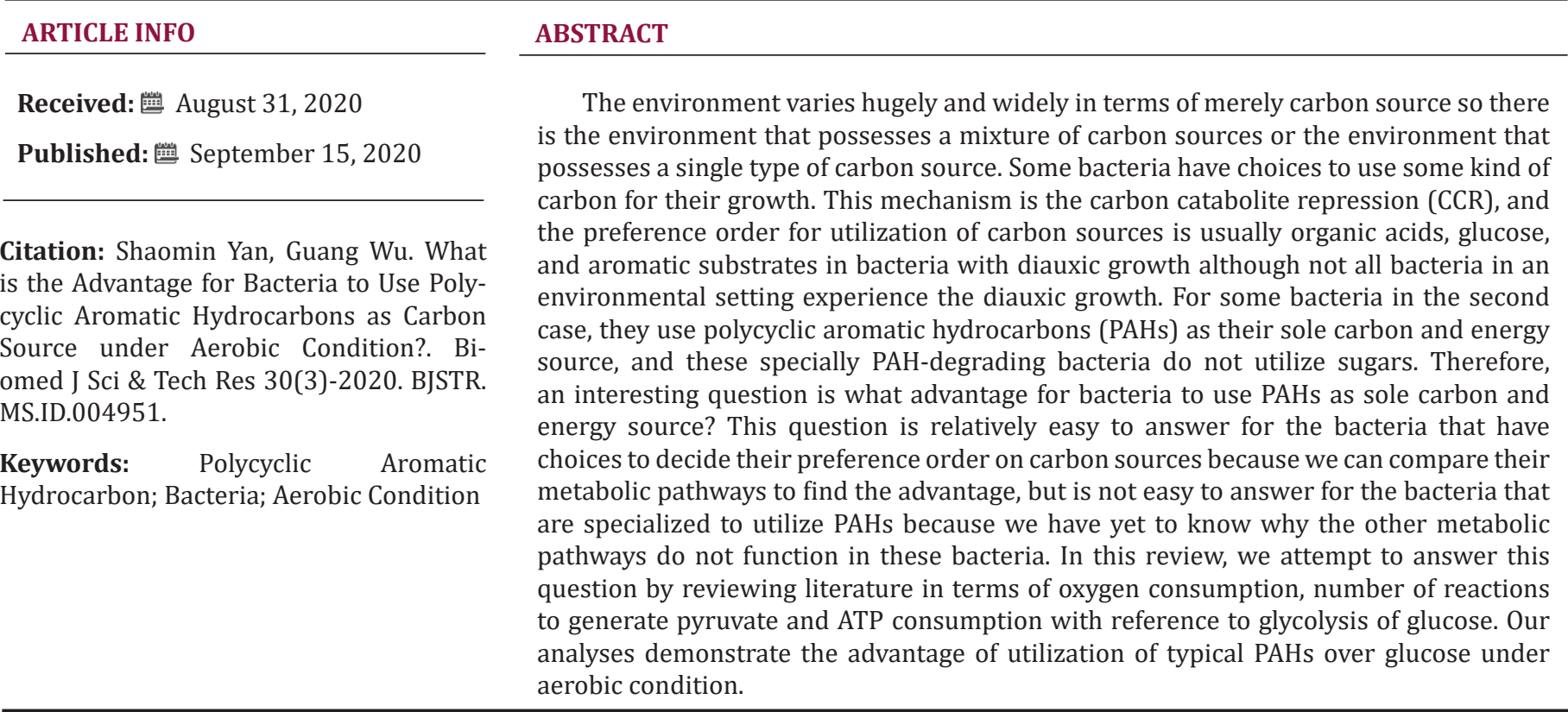

\section{Introduction}

The environment varies hugely and widely in terms of merely carbon source so there is the environment that possesses a mixture of carbon sources or the environment that possesses a single type of carbon source. Yet, bacteria are not selected in a particular environment just based on availability or supply of carbon substrates. For some bacteria in the first case, they have choices to use which carbon for their growth. This mechanism is the carbon catabolite repression (CCR), i.e. a bacterium uses its preferable carbon and inhibits transportation and metabolism of non-preferred carbons until the amount of preferable carbon is not sufficient $[1,2]$. This leads to the phenomenon of diauxic growth, i.e. the growth of bacteria has two log-phases although not all bacteria in an environmental setting experience the diauxic growth. The diauxic growth was observed in Bacillus subtilis for sucrose-dextran [3]; in Escherichia coli for glucose-lactose [4], glucose-melibiose [5] and glucose-glycerol [6]; in Lactobacillus casei for glucose-maltose [7] and glucose-ribose [7].

Although CCR is mainly related to the glycolysis and citric acid cycle, bacteria also evolved alternative metabolic pathways such as sugar metabolism via the keto-deoxy-phosphogluconate pathway (Entner-Doudoroff pathway) in Pseudomonas [8] because Pseudomonas lacks phosphofructokinase for glycolysis [9] and the 
pentose phosphate pathway [10]. Therefore, bacteria are able to live on various carbon sources. Indeed, Pseudomonas aeuroginosa PP4 and Pseudomonas sp. C5pp utilize glucose in their first logphase growth,but utilize aromatics in their second log-phase growth [11]. Further development shows that preference order for utilization of carbon sources in Pseudomonas is organic acids, glucose and aromatic substrates [12]. Intriguingly, not all species from Pseudomonas follow this preference order. For example, $P$. putida CSV86 utilizes aromatic substrates such as naphthalene, benzyl alcohol, benzoate, phenylacetic acid and phenylpropanoids (veratraldehyde, ferulic acid, vanillin and vanillic acid) prior to glucose [11-15]. This preference is very suggestive to biodegradation and bioremediation in environments [16], because pollution of aromatic compounds, especially, pollution of polycyclic aromatic hydrocarbons (PAHs), is harmful to humans and environments $[17,18]$. Accordingly, PAHs can be metabolized prior to other carbon sources. For bacteria, their uptake of PAHs requires

1) High-affinity systems,

2) Adhesion of PAHs to the solid substrate, and

3) Excretion of biosurfactant [19].

Although these requirements are relevant to uptake of PAHs, they are likely to be an indicator of CCR mechanism, which at first represses and then begins the synthesis of the enzymes for the transportation of less favorable carbon sources. In reality, P. putida CSV86 significantly expressed its ben locus in the first log phase and its glc locus in the second log phase when growing on glucose and benzoate [15]. Still, 3-day and $<1$ day lag phases in growth of Mycobacterium sp. strain CH1 with pyrene and phenanthrene or fluoranthene were observed [20]. Moreover, there are specialist PAH-degrading bacteria do not utilize sugars compared to generalist hydrocarbon-degrading organisms like Pseudomonas. An interesting question is what advantage for bacteria to use PAHs as sole carbon and energy source over other carbon sources? This question is relatively easy to answer for the bacteria that have choices to decide their preference order on carbon sources because we can compare their metabolic pathways to find the advantage, but is not easy to answer for the bacteria that are specialized to utilize PAHs because we have yet to know why the other metabolic pathways do not function in these bacteria. Indeed, it is hard to know how many carbon compounds in a certain environment are under the bacterial choices although pentose and hexose are the main choice in bacterial experiments. At this stage, we actually can only direct our attention to a small part of carbon sources, i.e. glucose as first step to approach to this topic. In this review, we attempt to answer this question by reviewing literature in terms of oxygen consumption, number of reactions to generate pyruvate and ATP consumption with reference to glycolysis of glucose.

\section{Aromatic Catabolism in General}

Although at least $660 \mathrm{PAH}$ structures have been documented [21], it is unknown how many PAHs bacteria can utilize. A review compiled 27 aromatic compounds, which can be utilized by around 40 bacterial species [22]. Thus, our knowledge on metabolism of aromatic compounds is limited to a small number of aromatic compounds including several typical PAHs. In fact, PAH bioremediation is dependent upon aerobic conditions [23]. Although aromatic compounds can serve as carbon source for bacteria, not all bacteria use aromatic compounds under aerobic condition. For example, $P$. aeruginosa is a facultative anaerobe living with partial or total oxygen depletion, under which it uses nitrate or nitrite as a terminal electron acceptor. When lacking of nitrate and nitrite, $P$. aeruginosa ferments arginine and pyruvate by substratelevel phosphorylation under anaerobic condition [24]. Utilization of aromatic compounds in bacteria not only means that a different preference order governed by CCR but also suggests the existence of additional mechanisms. For the latter case, Sinorhizobium, Rhizobium and Bradyrhizobium from $\alpha$-proteobacteria [25,26], and Pseudomonas from $\gamma$-proteobacteria [27] are in favor of acetate as well as intermediates in the citric acid cycle such as succinate rather than common carbon sources such as glucose, fructose or lactose. For Pseudomonads, the underlying mechanism is the involvement of catabolite repression control (Crc) protein [28-33]. For Rhizobacteria, the underlying mechanism is the involvement of inducer accumulation [26]. Indeed, different mechanisms lead to different metabolic pathways.

Thus an interesting question is whether the existence of oxygen could evolutionarily lead the different mechanisms to converge into a few pathways, which become less diverging? This rationale could be plausible because the oxygen environment should play an extremely important role on the bacterial evolution and give aerobic bacteria the energetic advantage over anaerobic bacteria. Really, the metabolism of PAHs in fungi and anaerobes are usually nonspecific [34], but many pathways converge to catecholic intermediates in aerobic microorganisms $[35,36]$. In this case, we just need to pay our attention to the limited number of pathways and some parts of a pathway, which are very classic in PAH studies. To a broader sense, technical revolution and globalization led many indigenous languages to extinction because they lose their local advantage and languages converge into few languages. Another example should be that the environmental changes led to extinction of megafauna.

\section{Starting and Ending Points for Comparison}

In order to find out the advantage of utilization of PAHs over glucose in bacteria, we should compare catabolism and metabolism of PAHs with glucose. The uptake of a molecule of glucose by bacteria through phosphoenolpyruvate(PEP):carbohydrate phosphotransferase system consumes an ATP [1]. On the other hand, it is still not clear which transport systems are responsible for uptake of aromatic compounds, so we have no ways to know whether the uptake of PAHs consumes ATP. Hence, our starting point for comparison should began from the time, when glucose and PAHs enter into bacterial cells because we have yet to know the exact mechanisms of uptake of aromatic compounds through 
bacterial membrane. Glucose can go through three catabolic pathways in bacteria:

i. $\quad$ the glycolysis, which produces pyruvate;

ii. the Entner-Doudoroff pathway, which produces pyruvate [8]; and

iii. the pentose phosphate pathway, which is mainly related to anabolism rather than catabolism [10].

For the last two pathways, their initial steps are the same from $\beta$-D-glucose 6-phosphate to 6-phospho-D-gluconate whereas the first two pathways can meet at KDPG (Figure 1), and then both glycolysis and Entner-Doudoroff pathway produce pyruvate. Importantly, these reactions do not need oxygen no matter of whether bacteria are under aerobic or anaerobic conditions. Thereafter, pyruvate goes through the citric acid cycle [37] requiring oxygen, i.e. bacteria must be under aerobic condition. In Figure 1, we can see an advantage in Pseudomonas, because it lacks phosphofructokinase for glycolysis [9] and the pentose phosphate pathway [10], so glucose can only go through the Entner-Doudoroff pathway, which has fewer reactions than glycolysis although produces fewer ATP. To our knowledge, it is not clear whether a bacterium prefers more reactions with big production of ATP or fewer reactions with small production of ATP. However, Figure 1 does show a species advantage for Pseudomonas. Naphthalene can also be metabolized to pyruvate before reaching catechol and gentisate in Figure 2, and both catechol and gentisate can further be catabolized to pyruvate [38-42]. Therefore, the ending point for comparison should be pyruvate, not only because it is the end product of glycolysis but also because it is reachable to PAHs. Hereafter, pyruvate can go to citric acid cycle under aerobic condition or go to fermentation under anaerobic condition. On the other hand, the comparison would be arbitrary because the intermediates in the citric acid cycle are different leading to the difficulty in comparison.

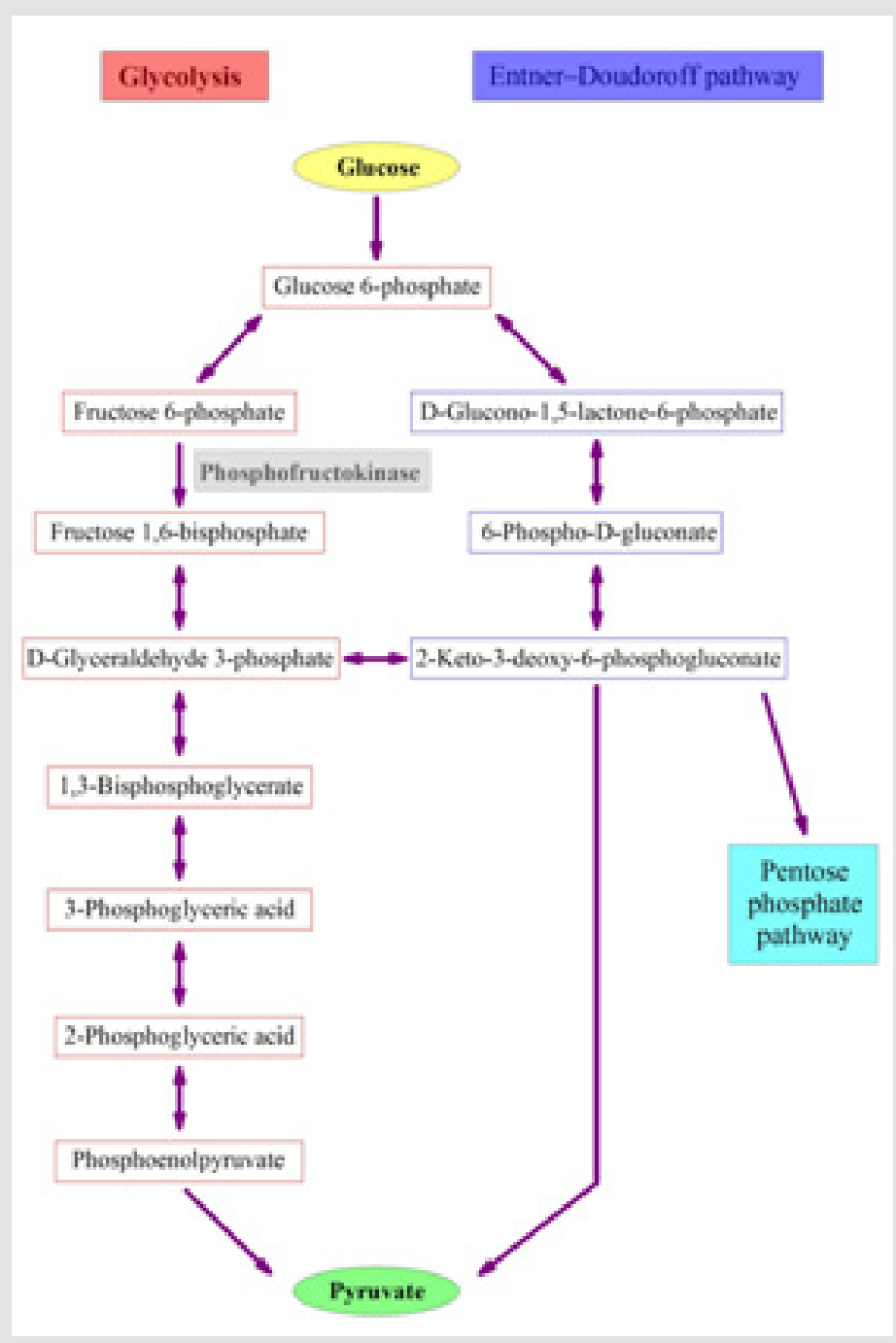

Figure 1: Three pathways for glucose metabolism before reaching pyruvate. 


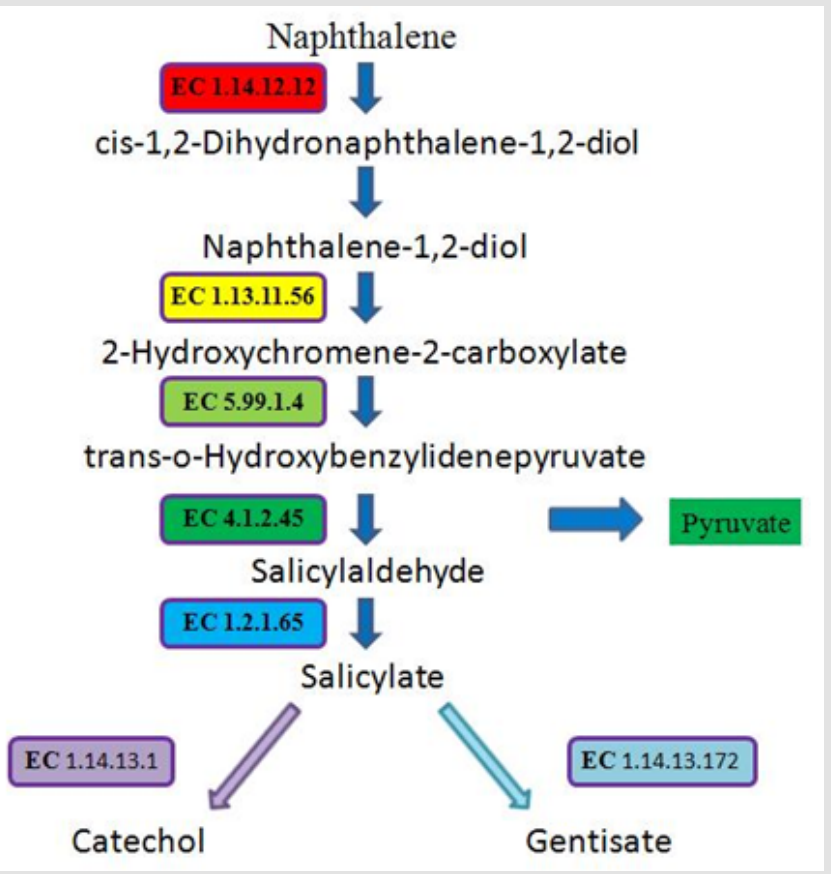

Figure 2: Catabolic pathways for naphthalene.

Again, if a bacterium prefers fewer reactions, then the choice of naphthalene has just five reactions to generate pyruvate whereas glycolysis needs ten reactions to generate pyruvate. For humans, the metabolism of PAHs aims to reduce their toxicity, whereas it is not clear whether bacteria have the same aim. However, it would be preferable to have the biological precursors such as pyruvate and acetyl coenzyme A, and fewer toxic intermediates such as o-quinones as metabolites [43-46]. This is the second reason to choose pyruvate as an ending point for comparison. We agree that the starting and ending points for comparison are debatable because there are many intermediate chemicals in degradation pathways. This is the dilemma between generalization and individuation: if we detail each intermediate chemical for comparison we lose the generalization, otherwise the comparison looks speculative and hypothetic. This is also the dilemma between simplification and sophistication: we cannot find the rules without simplification, but the rules always include exceptions. For this review, we had to make a compromise as an initial step towards future researches.

\section{From PAHs to Salicylate}

Although pyruvate is set as the ending point for comparison, salicylate is an important intermediate in Figure 2. In fact, the catabolic pathway of typical PAHs usually reaches to salicylate. As shown in Figure 2, 2-ring naphthalene reaches to salicylate through six reactions as follows $[38,47,48]$.

$$
\begin{aligned}
& \text { naphthalene }+\mathrm{O}_{2}+\mathrm{NADH}+\mathrm{H}^{+}<=>\text {cis-1,2-dihydronaphthalene }-1,2-\text { diol }+ \text { NAD } D^{+} \quad \text { Re. } 1 \\
& \text { cis-1,2-dihydronaphthalene-1,2-diol }+N A D^{+} \Leftrightarrow>\text { naphthalene-1,2-diol }+N A D H+H^{+} \text {Re. } 2 \\
& \text { naphthalene-1,2-diol }+\mathrm{O}_{2} \Leftrightarrow 2 \text {-hydroxychromene-2-carboxylate Re. } 3 \\
& \text { 2-hydroxychromene-2-carboxylate } \Leftrightarrow \text { trans -o-hydroxybenzylidenepyruvate Re. } 4 \\
& \text { trans }-\mathrm{o} \text {-hydroxybenzylidenepyruvate }+\mathrm{H}_{2} \mathrm{O} \Leftrightarrow>\text { salicylaldehyde }+ \text { pyruvate Re. } 5 \\
& \text { salicylaldehyde }+\mathrm{NAD}^{+}+\mathrm{H}_{2} \mathrm{O} \Leftrightarrow \text { salicylate }+\mathrm{NADH}+\mathrm{H}^{+} \quad \mathrm{Re} .6
\end{aligned}
$$

For net consumption and production, the degradation from naphthalene to salicylate consumes $\mathrm{NAD}^{+}, 2 \mathrm{O}_{2}$ and $2 \mathrm{H}_{2} \mathrm{O}$, but produces $\mathrm{NADH}, \mathrm{H}^{+}$and pyruvate. This pathway was called the upper catabolic pathway in P. putida G7 [38]. Comparing Figure 1 with Figure 2 and above six reactions, we can immediately find the advantage of utilization of naphthalene over glucose in terms of oxygen consumption, number of reactions to generate pyruvate and ATP consumption.

1) The pathway from naphthalene to salicylate consumes 2 oxygen molecules, whereas glycolysis does not need oxygen. 
2) Although salicylate is not the final product for naphthalene, pyruvate is already generated and the number of reactions to produce pyruvate is just 5 , whereas this requires ten reactions in glycolysis.

3) No ATP is needed for naphthalene, but ATP is needed in glycolysis, which though produces ATP eventually. Following this line of thought, we can look at other typical PAHs.

Fluorene has 3 rings, but only two are benzene rings. Although fluorene has three major catabolic pathways [42,49-53], it has a pathway to reach salicylate $[51,52]$. Anthracene has three benzene rings. Of its four catabolic pathways, there is a pathway to reach salicylate [38,54-56]. Figure 3 shows the net consumption and generation of molecules from typical PAHs to salicylate. However, this figure does not include typical 3-ring phenanthrene, 4-ring pyrene and 5-ring benzo[ $\alpha]$ pyrene, because they do not go through the pathways to salicylate. As can be seen in Figure 3, these PAHs already produce pyruvate before catabolizing to salicylate. On the other hand, the catabolism of salicylate will further produce pyruvate. This should be an advantage for bacteria to utilize PAHs. All these pathways from three PAHs to salicylate begin with naphthalene 1,2-dioxygenase (EC 1.14.12.12), which requires the first oxygen. Then the second oxygen is required for naphthalene with 1,2-dihydroxynaphthalene dioxygenase (EC 1.13.11.56), for fluorene with 3,4-dihydroxyfluorene 4,4a-dioxygenase (EC 1.13.11.), and for anthracene with anthracene-1,2-diol 1,2-dioxygenase meta-cleavage (EC 1.13.11.-).

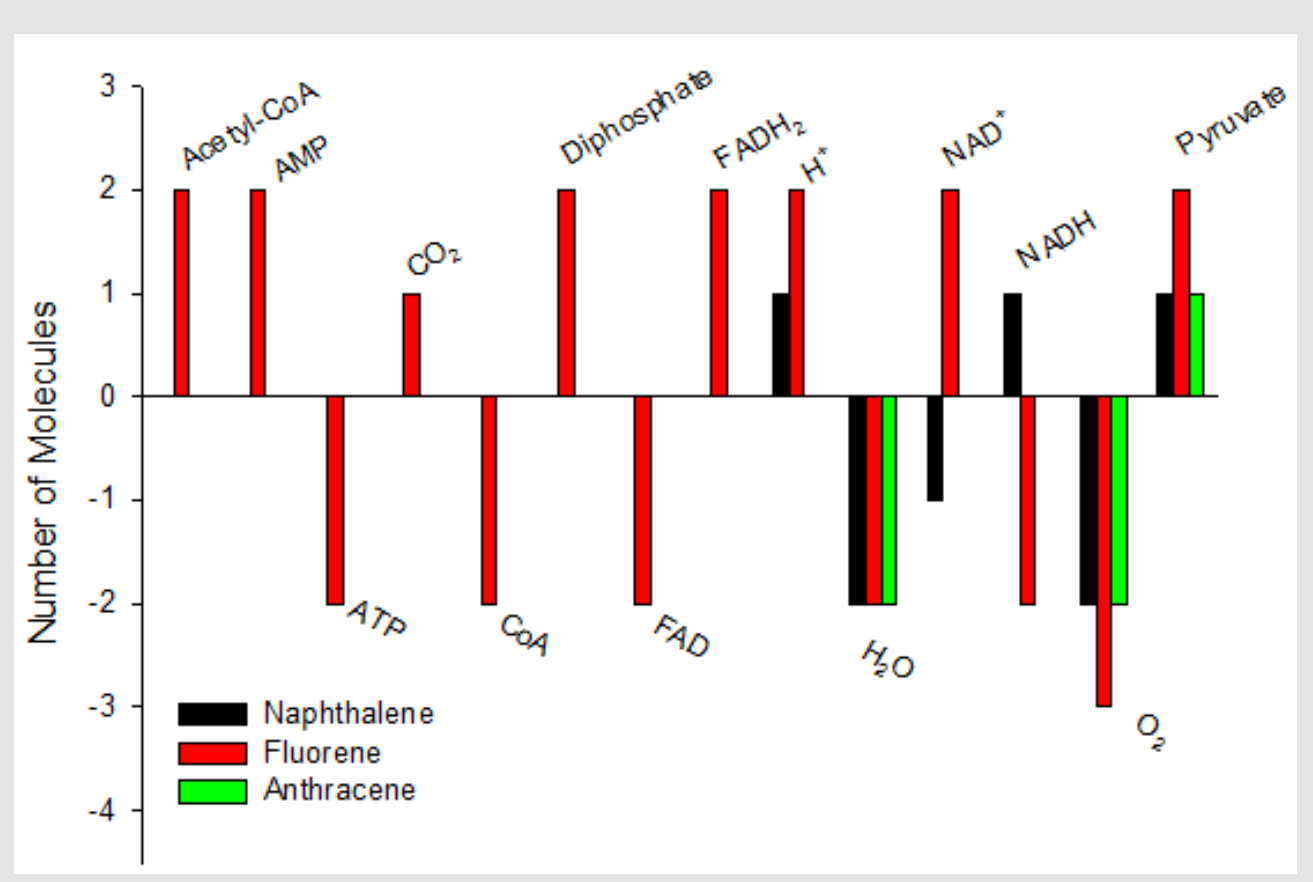

Figure 3: Net consumption and generation of molecules from naphthalene, fluorene and anthracene to salicylate.

These two oxygen-requiring reactions sufficiently take the advantage under aerobic condition. By clear contrast, glycolysis does not take this advantage under aerobic condition. Both fluorene and anthracene need only four reactions to generate pyruvate, but do not need ATP. Moreover, the glycolysis is a balanced reaction, so its reacted products can stay in bacteria without going to further reactions. By contrast, the pathways from PAHs to salicylate generate the products, which require further reactions such as diphosphate and $\mathrm{NAD}^{+}$. This prerequisite provides the base for further reactions. Actually, pyruvate is required for the uptake of glucose through phosphoenolpyruvate(PEP):carbohydrate phosphotransferase system [1], whereas the uptake of PAHs does not go through this system, thus the pyruvate generated by PAHs can be used for other purposes.

\section{From PAHs to Phthalate}

Compared with the pathways from PAHs to salicylate, the pathways from PAHs to phthalate appear to be widespread and efficient because fluorene, anthracene, phenanthrene and pyrene have the pathways to phthalate (Figure 4). Although phenanthrene and pyrene can reach salicylate, they have to go through naphthalene [57-60]. The pathways from PAHs to phthalate are more efficient because they have more reactions to use oxygen. Fluorene, anthracene and phenanthrene have three oxygen-requiring reactions, and pyrene has five oxygen-requiring reactions. Clearly, these reactions take fully the advantage in aerobic condition. For fluorene, the first oxygen-requiring reaction again needs naphthalene 1,2-dioxygenase (EC 1.14.12.12), which in fact serves as monooxygenase adds a single oxygen atom at 
fluorene and the other oxygen atom combines with $2 \mathrm{H}$ to become $\mathrm{H}_{2} \mathrm{O}$. The second oxygen-requiring reaction needs 9-fluorenone3,4-dioxygenase (EC 1.14.12.-), and the third oxygen-requiring reaction needs 2,3-dihydroxy-2'-carboxybiphenyl 1,2-dioxygenase (EC 1.13.---). Although this pathway looks efficient, only 7.4\% initial fluorene went through it in Arthrobacter sp. strain F101 [52].

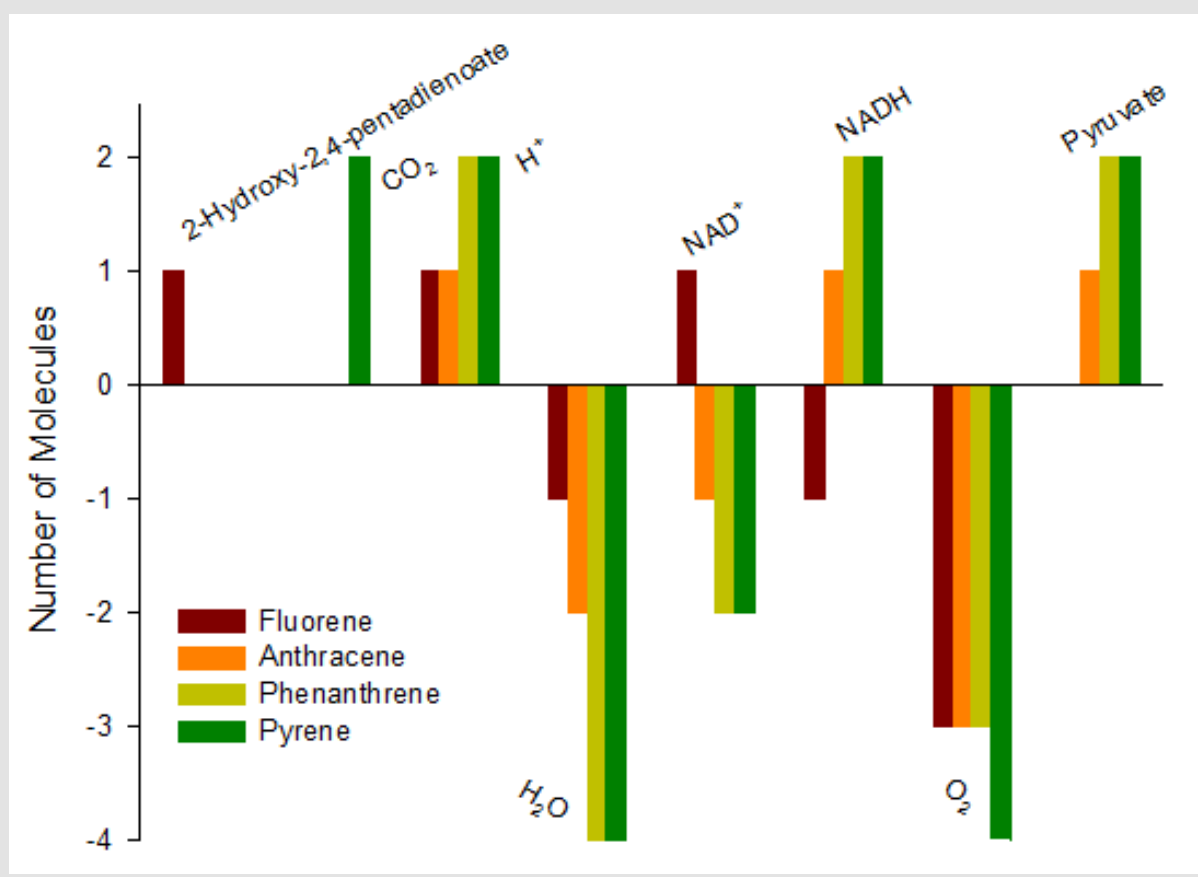

Figure 4: Net consumption and generation of molecules from fluorene, anthracene, phenanthrene and pyrene to phthalate.

For anthracene, the first oxygen-requiring reaction again needs naphthalene 1,2-dioxygenase (EC 1.14.12.12), the second oxygenrequiring reaction needs anthracene-1,2-diol 1,2-dioxygenase (EC 1.13.11.-), and the third oxygen-requiring reaction needs 3-hydroxy-2-naphthoate 2,3-dioxygenase (EC 1.13.11.-). In fact, this pathway is more complicated than the pathway to salicylate; however, it consumes one more oxygen molecules than the pathway to salicylate. Thus it is not clear whether a bacterium deliberately does so. For phenanthrene, the first oxygen-requiring reaction needs phenathrene dioxygenase (EC 1.13.11.-), the second oxygenrequiring reaction needs extradiol dioxygenase (EC 1.13.11.-), and the third oxygen-requiring reaction needs 1-hydroxy-2-naphthoate dioxygenase (EC 1.13.11.38). Although this pathway consumes three oxygen molecules, phenanthrene can pass around 1-hydroxy2-naphthoate dioxygenase (EC 1.13.11.38) to naphthalene degradation to salicylate, which requires total four oxygen molecules. For pyrene, the first oxygen-requiring reaction needs pyrene dioxygenase (EC 1.14.---), the second oxygen-requiring reaction needs 4,5-dihydroxypyrene dioxygenase (EC 1.13.11.-), and the third oxygen-requiring reaction needs phenanthrene-4carboxylate dioxygenase (EC 1.14.12.-), from here the reactions go to the phenanthrene pathway to consume additional two oxygen molecules to reach phthalate requiring a total five oxygen molecules, or pass around 1-hydroxy-2-naphthoate dioxygenase (EC 1.13.11.38) to naphthalene degradation to reach salicylate requiring total six oxygen molecules. In comparison with glycolysis, a lot of oxygen molecules are consumed in the pathways from PAHs to phthalate, so PAHs catabolism takes fully the advantage of aerobic condition.

In terms of the number of reactions to generate pyruvate, anthracene and phenanthrene need four and five reactions, respectively, while pyrene needs 9 and 12 reactions to generate its first and second pyruvates. The pathways to phthalate also produce pyruvate except for fluorene. Moreover, they do not require as many reactions as glycolysis to generate pyruvate. This is also an advantage of PAHs over glucose. In terms of ATP, these four typical PAHs do not consume ATP to reach phthalate. Comparing Figure 4 with Figure 3, it is clear that the pathways from PAHs to phthalate are simpler than the pathways from PAHs to salicylate because these pathways do not require complicated molecules, for example, CoA in fluorene. This is very meaningful because CoA can be used to form benzoyl-CoA or methyl-benzoyl-CoA, which then can be used by bacteria under anaerobic conditions [61].

\section{Other Pathways}

In addition to salicylate and phthalate, there are several minor pathways to generate different products. For fluorene, it goes to 3-chromanone [50,52,62], which requires $2 \mathrm{H}^{+}, 2 \mathrm{NADH}, 2 \mathrm{H}_{2} \mathrm{O}$ and $3 \mathrm{O}_{2}$, but produces $2 \mathrm{e}^{-}, 2 \mathrm{NAD}^{+}, \mathrm{CO}_{2}$ and pyruvate. Actually, this pathway is very efficient because it has five reactions but needs three 
oxygen molecules, and produces pyruvate in the third reaction. The first oxygen molecule is added together two $\mathrm{H}^{+}$by a dioxygenase. Actually, the first step in this pathway and the pathway to salicylate is the oxidation to dihydrodiol products. For anthracene, it goes to 9,10-anthraquinone, which requires $\mathrm{O}_{2}$ and $2 \mathrm{e}$; but produces 2 $\mathrm{H}^{+}$. Although this pathway requires oxygen, it does not produce pyruvate, and stops at 9,10-anthraquinone. In another pathway, anthracene goes to 3-(2-carboxyvinyl)naphthalene-2-carboxylic acid, which requires two oxygen molecules but does not generate pyruvate, and 3-(2-carboxyvinyl)naphthalene-2-carboxylic acid is the end product. Anyway, these two pathways have yet to find their further catabolic pathways so far [63] although the difference between the pathway to 9,10 -anthraquinone and the pathway to salicylate is the difference between anthracene-cis-1,2-dihydrodiol and anthracene-9,10-dihydrodiol. For pyrene, 6,6-dihydroxy-2,2-biphenyl dicarboxylic acid implies the dioxygenation on 4,5 positions and 9,10 positions, and the cleavage on both central rings [64].

The abovementioned dihydroxylated intermediates may then be catabolized by either an ortho-cleavage pathway or a metacleavage pathway [65]. For phenanthrene, two minor pathways going to 9-phenanthrol and 1-methoxy-phenanthrene, which are still 3-ring compounds and have yet to find their further catabolic pathways so far [63]. However, the initial step in these two pathways is an addition of single oxygen atom by a hydroxylase serving as mono-oxygenase. Benzo[ $\boldsymbol{\alpha}]$ pyrene is also a typical PAH. Because of its five benzene rings, but few bacteria can catabolize it such as Mycobacterium sp. [66-68], Sphingomonas paucimobilis [69]

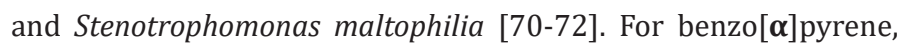
its initial step in the aerobic catabolism is also the oxidation to a dihydrodiol at almost all double carbon bond position: benzo[ $[\boldsymbol{\alpha}]$ pyrene-cis-4,5-dihydrodiol, benzo[ $\alpha]$ pyrene-cis-7,8-dihydrodiol,

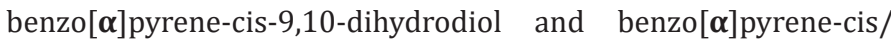
trans-11,12-dihydrodiol. Accordingly, 4-ring benz[ $\boldsymbol{\alpha}]$ anthracene can also be catabolized in a similar manner $[68,73]$. But it is still not much known on the further catabolic mechanism for 5-ring to 4-ring PAHs [74-77].

\section{Final Step to Pyruvate}

After reaching salicylate from PAHs, salicylate can be catabolized to catechol, consuming $\mathrm{H}^{+}$, $\mathrm{NADH}$ and $\mathrm{O}_{2}$, and producing $\mathrm{CO}_{2}, \mathrm{H}_{2} \mathrm{O}$ and $\mathrm{NAD}^{+}$. From salicylate to pyruvate and acetaldehyde in naphthalene catabolism was called the lower catabolic pathway through the catechol meta-cleavage pathway $[38,41,47,48]$. Thereafter, catechol can produce pyruvate as consuming $2 \mathrm{H}_{2} \mathrm{O}, \mathrm{CoA}, \mathrm{NAD}^{+}$and $\mathrm{O}_{2}$, and producing formate, $\mathrm{H}^{+}, \mathrm{NADH}$ and pyruvate. Nevertheless, catechol consumes $\mathrm{O}_{2}, \mathrm{H}_{2} \mathrm{O}$, acetyl-CoA and succinyl-CoA but produces CoA and succinate, which are carbon source for Sinorhizobium, Rhizobium, Bradyrhizobium [25,26] and Pseudomonas [27]. For phthalate, it can produce 2 pyruvates and formate consuming $2 \mathrm{H}_{2} \mathrm{O}$ and $2 \mathrm{O}_{2}$, and generating $\mathrm{CO}_{2}$. In fact, phthalate is very important because many pathways channel to it. For instance, the catabolism of fluoranthene in M. vanbaalenii PYR-1 is initiated by mono- and di-oxygenation reactions in four pathways routing to phthalate, which then goes to $\boldsymbol{\beta}$-ketoadipate pathway to become intermediates in citric acid cycle [78]. For gentisate, it can go to pyruvate and fumarate consuming $\mathrm{O}_{2}$ and $\mathrm{H}_{2} \mathrm{O}$. Table 1 summarizes the pathways from glucose to pyruvate and from typical PAHs to pyruvate. As can be seen in this table, the low-molecular-weight PAHs do not have too many reactions compared with glucose to be catabolized to pyruvate. However, PAHs do not generate ATP during their catabolism to pyruvate.

Table 1: Comparison of pathways from glucose to pyruvate and from typical PAHs to pyruvate (the pathways were obtained by combining of reactions from KEGG [63] together).

\begin{tabular}{|c|c|c|}
\hline Pathways & $\begin{array}{l}\text { Number of } \\
\text { Reactions }\end{array}$ & Via \\
\hline glucose $+2 \mathrm{NAD}^{+}+2 \mathrm{ADP}+2 \mathrm{P}_{\mathrm{i}}==>2$ pyruvate $+2 \mathrm{NADH}+2 \mathrm{H}^{+}+2 \mathrm{ATP}+2 \mathrm{H}_{2} \mathrm{O}$ & 10 & \\
\hline naphthalene $+4 \mathrm{O}_{2}+3 \mathrm{H}_{2} \mathrm{O}==>2$ pyruvate + acetaldehyde + formate $+\mathrm{CO}_{2}$ & 11 & $\begin{array}{c}\text { salicylate } \\
\text { catechol }\end{array}$ \\
\hline naphthalene $+4 \mathrm{O}_{2}+2 \mathrm{H}_{2} \mathrm{O}==>2$ pyruvate + fumarate & 10 & gentisate \\
\hline $\begin{array}{c}2 \text { fluorene }+2 \mathrm{ATP}+2 \mathrm{CoA}+2 \mathrm{FAD}+6 \mathrm{H}_{2} \mathrm{O}+4 \mathrm{NADH}+10 \mathrm{O}_{2}==>2 \text { acetaldehyde }+2 \text { acetyl-CoA }+2 \mathrm{AMP}+2 \\
\text { diphosphate }+2 \mathrm{FADH}_{2}+2 \text { formate }+3 \mathrm{CO}_{2}+4 \mathrm{NAD}^{+}+4 \text { pyruvate }\end{array}$ & 13 & $\begin{array}{l}\text { naphthalene } \\
\text { salicylate } \\
\text { catechol }\end{array}$ \\
\hline 2 fluorene $+2 \mathrm{H}^{+}+2 \mathrm{NADH}+8 \mathrm{H}_{2} \mathrm{O}+7 \mathrm{O}_{2}==>4 \mathrm{e}^{-}+2 \mathrm{NAD}^{+}+2$ acetaldehyde $+2 \mathrm{CO}_{2}+2$ formate +4 pyruvate & 10 & 3-chromanone \\
\hline fluorene $+3 \mathrm{H}_{2} \mathrm{O}+\mathrm{NADH}+5 \mathrm{O}_{2}==>\mathrm{H}^{+}+\mathrm{NAD}^{+}+\mathrm{CO}_{2}+$ formate +2 pyruvate +2 -hydroxy-2,4-pentadienoate & 13 & phthalate \\
\hline anthracene $+\mathrm{H}^{+}+3 \mathrm{H}_{2} \mathrm{O}+\mathrm{NADH}+4 \mathrm{O}_{2}==>$ acetaldehyde $+\mathrm{CO}_{2}+$ formate $+\mathrm{NAD}^{+}+2$ pyruvate & 11 & $\begin{array}{c}\text { salicylate } \\
\text { catechol }\end{array}$ \\
\hline anthracene $+4 \mathrm{H}_{2} \mathrm{O}+\mathrm{NAD}^{+}+5 \mathrm{O}_{2}==>\mathrm{CO}_{2}+$ formate $+\mathrm{NADH}+3$ pyruvate & 14 & phthalate \\
\hline phenanthrene $+4 \mathrm{H}_{2} \mathrm{O}+6 \mathrm{O}_{2}==>$ acetaldehyde $+2 \mathrm{CO}_{2}+$ formate +3 pyruvate & 16 & catechol \\
\hline phenanthrene $+6 \mathrm{H}_{2} \mathrm{O}+2 \mathrm{NAD}^{+}+5 \mathrm{O}_{2}==>\mathrm{CO}_{2}+$ formate $+2 \mathrm{H}^{+}+2 \mathrm{NADH}+4$ pyruvate & 16 & phthalate \\
\hline pyrene $+6 \mathrm{H}_{2} \mathrm{O}+2 \mathrm{NAD}^{+}+7 \mathrm{O}_{2}==>3 \mathrm{CO}_{2}+$ formate $+2 \mathrm{H}^{+}+2 \mathrm{NADH}+4$ pyruvate & 20 & phthalate \\
\hline
\end{tabular}


The metabolic network for 10 PAHs in M. vanbaalenii PYR1 includes 183 metabolites and 224 chemical reactions [46]. Although typical PAHs can go through two major pathways to pyruvates, i.e. catechol and phthalate, it seems that phthalate may be preferable. For example, although phenanthrene can go through catechol pathway to pyruvate, i.e. a part of pathway of catabolim of naphthalene, bacteria using ortho-cleavage mechanism cannot grow up with naphthalene as sole carbon source [79,80]. Nevertheless, the generation of energy is not the only determinant factor to decide the PAH catabolic pathways. For example, the catabolism of fluoranthene in M. vanbaalenii PYR-1 can go C-1,2, C-7,8 and $\mathrm{C}-8,9$ dioxygenation pathways but not in the C-2,3 dioxygenation pathway [81]. An important aspect is whether bacteria deliberate to channel PAHs towards more productivity and less toxicity, which was considered to be related to pleiotropic and epistatic functional responsibility in enzymes [81]. Furthermore, there are bacteria that can utilize PAH as sole carbon and energy source, such genera are Cycloclasticus [82,83], Porticoccus hydrocarbonoclasticus [84,85], Neptunomonas [86], Algiphilus [87,88].

These bacteria are marine bacteria, which draw much attention recently. However, the marine environments are quite different from the environments, where our familiar bacteria live. In fact, most of our current knowledge on carbon metabolism and PAH degradation comes from bacteria living in the land environments. Therefore, it is still difficult to apply our analysis to the marine bacteria with respect to each metabolic pathway. Anyway, these marine bacteria might have already evolved to the stage that they can solely use PAHs without utilization of sugar, which on the other side demonstrates the advantage of utilization of PAHs over other carbon sources. An important issue that is not clear to us is whether an enzymatic reaction can be clarified as endothermic or exothermic although we certainly know that these enzymatic reactions either absorbing of heat or releasing of heat. This is because it is often mentioned that an enzyme reduces the activation energy for a chemical reaction, but without indicating whether the reaction is endothermic or exothermic.

\section{Conclusion}

It is not clear whether each reaction in PAHs catabolism is endothermic or exothermic, thus we have no way to determine the advantage from viewpoint of heat consumption and generation. In this review, the analyses were conducted according to three comparison criteria, oxygen consumption, number of reactions to generate pyruvate and ATP consumption with reference to glycolysis of glucose. Our review demonstrates the advantages of utilization of PAHs over glucose under aerobic condition. We have yet to address the advantage of cometabolic biodegradation, which was shown as early as 70s in last century [89], and whether there is a possible advantage under anaerobic condition. However, it is unlikely to find such advantage of utilization of PAHs over glucose under anaerobic condition.

\section{Funding}

This study was partly supported by National Natural Science Foundation of China (No. 31460296 and 31560315), Key Project of Guangxi Scientific Research and Technology Development Plan (AB17190534).

\section{Conflict of Interest Statement}

The authors declare that the research was conducted in the absence of any commercial or financial relationships that could be construed as a potential conflict of interest.

\section{References}

1. Deutscher J, Francke C, Postma PW (2006) How phosphotransferase system-related protein phosphorylation regulates carbohydrate metabolism in bacteria. Microbiol Mol Biol Rev 70: 939-1031.

2. Görke B, Stülke J (2008) Carbon catabolite repression in bacteria: many ways to make the most out of nutrients. Nat Rev Microbiol 6(8): 613624.

3. Monod J (1942) Recherches sur la croissance des cultures bactériennes. Hermann et Cie, Paris, France.

4. Inada T, Kimata K, Aiba H (1996) Mechanism responsible for glucoselactose diauxie in Escherichia coli: challenge to the cAMP model. Genes Cells 1(3): 293-301.

5. Okada T, Ueyama K, Niiya S, Kanazawa H, Futai M, et al. (1981) Role of inducer exclusion in preferential utilization of glucose over melibiose in diauxic growth of Escherichia coli. J Bacteriol 146(3): 1030-1037.

6. Holtman CK, Pawlyk AC, Meadow ND, Pettigrew DW (2001) Reverse genetics of Escherichia coli glycerol kinase allosteric regulation and glucose control of glycerol utilization in vivo. J Bacteriol 183(11): 33363344.

7. Viana R, Monedero V, Dossonnet V, Vadeboncoeur C, Pérez Martínez G, et al. (2000) Enzyme I and HPr from Lactobacillus casei: their role in sugar transport, carbon catabolite repression and inducer exclusion. Mol Microbiol 36(3): 570-584.

8. Entner N, Doudoroff M (1952) Glucose and gluconic acid oxidation of Pseudomonas saccharophila. J Biol Chem 196(2): 853-862.

9. Conway T (1992) The Entner-Doudoroff pathway: history, physiology and molecular biology. FEMS Microbiol Rev 9(1): 1-27.

10. Stincone A, Prigione A, Cramer T, Wamelink MM, Campbell K, et al. (2015) The return of metabolism: biochemistry and physiology of the pentose phosphate pathway. Biol Rev Camb Philos Soc 90(3): 927-963.

11. Karishma M, Trivedi VD, Choudhary A, Mhatre A, Kambli P, et al. (2015) Analysis of preference for carbon source utilization among three strains of aromatic compounds degrading Pseudomonas. FEMS Microbiol Lett 362(20): fnv139.

12. Rojo F (2010) Carbon catabolite repression in Pseudomonas: optimizing metabolic versatility and interactions with the environment. FEMS Microbiol Rev 34(5): 658-684.

13. Basu A, Apte SK, Phale PS (2006) Preferential utilization of aromatic compounds over glucose by Pseudomonas putida CSV86. Appl Environ Microbiol 72(3): 2226-30.

14. Basu A, Shrivastava R, Basu B, Apte SK, Phale PS (2007) Modulation of glucose transport causes preferential utilization of aromatic compounds in Pseudomonas putida CSV86. J Bacteriol 189(21): 7556-7562.

15. Choudhary A, Modak A, Apte SK, Phale PS (2017) Transcriptional modulation of transport- and metabolism-associated gene clusters leading to utilization of benzoate in preference to glucose in Pseudomonas putida CSV86. Appl Environ Microbiol 83(19): e01280-17. 
16. Peng RH, Xiong AS, Xue Y, Fu XY, Gao F, et al. (2008) Microbial biodegradation of polyaromatic hydrocarbons. FEMS Microbiol Rev 32(6): 927-955.

17. Yan S, Wu G (2017) Reorganization of gene network for degradation of polycyclic aromatic hydrocarbons (PAHs) in Pseudomonas aeruginosa PA01 under several conditions. J Appl Genet 58(4): 545-563.

18. Yan S, Wu G (2020) Uptake of polycyclic aromatic hydrocarbons in bacteria. Advances in Microbiology 10.

19. Wick LY, Munain ARD, Springael D, Harms H (2002) Responses of Mycobacterium sp. LB501T to the low bioavailability of solid anthracene. Appl Microbiol Biotechnol 58(3): 378-385

20. Churchill SA, HarperJP, Churchill PF (1999) Isolation and characterization of a Mycobacterium species capable of degrading three- and four-ring aromatic and aliphatic hydrocarbons. Appl Environ Microbiol 65(2): 549-552.

21. Sander LC, Wise SA (2011) Polycyclic aromatic hydrocarbon structure index. NIST Special Publication 922, National Institute of Standards and Technology, United Sates Department of Commerce Technology Administration, Gaithersburg, MD 20899-0001.

22. Seo JS, Keum YS, Li QX (2009) Bacterial degradation of aromatic compounds. Int J Environ Res Public Health 6(1): 278-309.

23. Fritzsche C (1994) Degradation of pyrene at low defined oxygen concentrations by a Mycobacterium sp. Appl Environ Microbiol 60(5): $1687-1689$.

24. Schobert M, Jahn D (2010) Anaerobic physiology of Pseudomonas aeruginosa in the cystic fibrosis lung. Int J Med Microbiol 300(8): 549556.

25. Ucker DS, Signer ER (1978) Catabolite-repression-like phenomenon in Rhizobium meliloti. J Bacteriol 136(3): 1197-1200.

26. Bringhurst RM, Gage DJ (2002) Control of inducer accumulation plays a key role in succinate-mediated catabolite repression in Sinorhizobium meliloti. J Bacteriol 184(19): 5385-5392.

27. Collier DN, Hager PW, Phibbs PVJr (1996) Catabolite repression control in the pseudomonads. Res Microbiol 147(6-7): 551-561.

28. Hester KL, Lehman J, Najar F, Song L, Roe BA, et al. (2000) Crc is involved in catabolite repression control of the bkd operons of Pseudomonas putida and Pseudomonas aeruginosa. J Bacteriol 182(4): 1144-1149.

29. Hester KL, Madhusudhan KT, Sokatch JR (2000) Catabolite repression control by $\mathrm{Crc}$ in 2xYT medium is mediated by posttranscriptional regulation of bkdR expression in Pseudomonas putida. J Bacteriol 182(4): 1150-1153.

30. Yuste L, Rojo F (2001) Role of the crc gene in catabolic repression of the Pseudomonas putida GPo1 alkane degradation pathway. J Bacteriol 183(21): 6197-6206

31. Morales G, Linares JF, Beloso A, Albar JP, Martínez JL, et al. (2004) The Pseudomonas putida Crc global regulator controls the expression of genes from several chromosomal catabolic pathways for aromatic compounds. J Bacteriol 186(5): 1337-1344.

32. Aranda Olmedo I, Ramos JL, Marqués S (2005) Integration of signals through Crc and PtsN in catabolite repression of Pseudomonas putida TOL plasmid pWW0. Appl Environ Microbiol 71(8): 4191-4198.

33. Ruiz Manzano A, Yuste L, Rojo F (2005) Levels and activity of the Pseudomonas putida global regulatory protein Crc vary according to growth conditions. J Bacteriol 187(11): 3678-3686.

34. Spain JC (1995) Biodegradation of nitroaromatic compounds. Annu Rev Microbiol 49: 523-555

35. Dunwell JM, Culham A, Carter CE, Sosa Aguirre CR, Goodenough PW (2001) Evolution of functional diversity in the cupin superfamily Trends. Biochem Sci 26(12): 740-746.
36. Khuri S, Bakker FT, Dunwell JM (2001) Phylogeny, function, and evolution of the cupins, a structurally conserved, functionally diverse superfamily of proteins. Mol Biol Evol 18(4): 593-605.

37. Porter RK, Brand MD (1995) Mitochondrial proton conductance and $\mathrm{H}+/ \mathrm{O}$ ratio are independent of electron transport rate in isolated hepatocytes. Biochem J 310(Pt 2):379-382.

38. Denome SA, Stanley DC, Olson ES, Young KD (1993) Metabolism of dibenzothiophene and naphthalene in Pseudomonas strains: Complete DNA sequence of an upper naphthalene catabolic pathway. J Bacteriol 175(21): 6890-6901.

39. Kiyohara H, Torigoe S, Kaida N, Asaki T, Iida T, et al. (1994) Cloning and characterization of a chromosomal gene cluster, pah, that encodes the upper pathway for phenanthrene and naphthalene utilization by Pseudomonas putida OUS82. J Bacteriol 176(8): 2439-2443.

40. Auger RL, Jacobson AM, Domach MM (1995) Effect of nonionic surfactant addition on bacterial metabolism of naphthalene: Assessment of toxicity and overflow metabolism potential. J Hazard Mater 43(3): 263-272.

41. Goyal AK, Zylstra GJ (1997) Genetics of naphthalene and phenanthrene degradation by Comamonas testosterone. J Ind Microbiol Biotechnol 19(5-6): 401-407.

42. Baboshin M, Akimov V, Baskunov B, Born TL, Khan SU, et al. (2008) Conversion of polycyclic aromatic hydrocarbons by Sphingomonas sp. VKM B-2434. Biodegradation 19(4): 567-576.

43. Heitkamp MA, Freeman JP, Miller DW, Cerniglia CE (1988) Pyrene degradation by a Mycobacterium sp.: Identification of ring oxidation and ring fission products. Appl Environ Microbiol 54(10): 2556-2565.

44. Cerniglia CE (1992) Biodegradation of polycyclic aromatic hydrocarbons. Biodegradation 3: 351-368.

45. Kim YH, Moody JD, Freeman JP, Engesser KH, Cerniglia CE (2004) Evidence for the existence of PAH-quinone reductase and catechol-Omethyltransferase in Mycobacterium vanbaalenii PYR-1. J Ind Microbiol Biotechnol 31: 507-516.

46. Kweon O, Kim SJ, Holland RD, Chen H, Kim DW, et al. (2011) Polycyclic aromatic hydrocarbon-metabolic network in Mycobacterium vanbaalenii PYR-1. J Bacteriol 193(17): 4326-4337.

47. Simon MJ, Osslund TD, Saunders R, Ensley BD, Suggs S, et al. (1993) Sequences of genes encoding naphthalene dioxygenase in Pseudomonas putida strains G7 and NCIB 9816-4. Gene 127(1): 31-37.

48. Goyal AK, Zylstra GJ (1996) Molecular cloning of novel genes for polycyclic aromatic hydrocarbon degradation from Comamonas testosteroni GZ39. Appl Environ Microbiol 62(1): 230-236.

49. Boldrin B, Tiehm A, Fritzsche C (1993) Degradation of phenanthrene, fluorene, fluoranthene, and pyrene by a Mycobacterium sp. Appl Environ Microbiol 59(6): 1927-1930.

50. Monna L, Omori T, Kodama T (1993) Microbial degradation of dibenzofuran fluorene and dibenzo-p-dioxin by Staphylococcus auriculans DBF63. Appl Environ Microbiol 59(1): 285-289.

51. Grifoll M, Selifonov SA, Chapman PJ (1995) Transformation of substituted fluorenes and fluorene analogs by Pseudomonas sp. strain F274. Appl Environ Microbiol 61(9): 3490-3493.

52. Casellas M, Grifoll M, Bayona JM, Solanas AM (1997) New metabolites in the degradation of fluorene by Arthrobacter sp. strain F101. Appl Environ Microbiol 63(3): 819-826.

53. Wattiau P, Bastiaens L, Van Herwijnen R, Daal L, Parsons JR, et al. (2001) Fluorene degradation by Sphingomonas sp. LB126 proceeds through protocatechuic acid: a genetic analysis. Res Microbiol 152(10): 861-872.

54. Patel TR, Gibson DT (1974) Purification and propeties of (plus)-cisnaphthalene dihydrodiol dehydrogenase of Pseudomonas putida. J Bacteriol 119(3): 879-888. 
55. Axcell BC, Geary PJ (1973) The metabolism of benzene by bacteria Purification and some properties of the enzyme cis-1,2 dihydroxycyclohexa-3,5-diene (nicotinamide adenine dinucleotide) oxidoreductase (cis-benzene glycol dehydrogenase). Biochem J 136(4): 927-934.

56. Jouanneau Y, Meyer C, Jakoncic J, Stojanoff V, Gaillard J (2006) Characterization of a naphthalene dioxygenase endowed with an exceptionally broad substrate specificity toward polycyclic aromatic hydrocarbons. Biochemistry 45(40): 12380-12391.

57. Kim YH, Freeman JP (2005) Effects of $\mathrm{pH}$ on the degradation of phenanthrene and pyrene by Mycobacterium vanbaalenii PYR-1. Appl Microbiol Biotechnol 67(2): 275-285.

58. Seo JS, Keum YS, Hu Y, Lee SE, Li QX (2006) Phenanthrene degradation in Arthrobacter sp. P1-1: Initial 1,2- 3,4- and 9,10-dioxygenation and meta- and ortho-cleavages of naphthalene-1,2-diol after its formation from naphthalene-1,2-dicarboxylic acid and hydroxyl naphthoic acids. Chemosphere 65(11): 2388-2394.

59. Pagnout C, Frache G, Poupin P, Maunit B, Muller JF, et al. (2007) Isolation and characterization of a gene cluster in $\mathrm{PAH}$ degradation in Mycobacterium sp. strain SNP11: Expression in Mycobacterium smegmatis mc(2)155. Res Microbiol 158(2): 175-186.

60. Seo JS, Keum YS, Hu Y, Lee SE, Li QX (2007) Degradation of phenanthrene by Burkholderia sp. C3: Initial 1,2- and 3,4-dioxygenation and meta- and ortho-cleavages of naphthalene-1,2-diol. Biodegradation 18(1): 123131.

61. Boll M, Fuchs G, Heider J (2002) Anaerobic oxidation of aromatic compounds and hydrocarbons. Curr Opin Chem Biol 6(5): 604-611.

62. Habe H, Chung JS, Kato H, Ayabe Y, Kasuga K, et al. (2004) Characterization of the upper pathway genes for fluorene metabolism in Terrabacter $s p$ strain DBF63. J Bacteriol 186(17): 5938-5944

63. Kanehisa M, Furumichi M, Tanabe M, Sato Y, Morishima K (2017) KEGG: new perspectives on genomes, pathways, diseases and drugs. Nucleic Acids Res 45(D1): D353-D361.

64. Vila J, López Z, Sabate J, Minguillon C, Solanas AM, et al. (2001) Identification of a novel metabolite in the degradation of pyrene by Mycobacterium sp. strain AP1: actions of the isolate on two- and threering polycyclic aromatic hydrocarbons. Appl Environ Microbiol 67: 5497-5505.

65. Van der Meer JR, de Vos WM, Harayama S, Zehnder AJB (1992) Molecular mechanisms of genetic adaptation to xenobiotic compounds. Microbiol Rev 56(4): 677-694.

66. Heitkamp MA, Cerniglia CE (1989) Polycyclic aromatic hydrocarbon degradation by a Mycobacterium sp. in microcosm containing sediment and water from a pristine ecosystem. Appl Environ Microbiol 55(8): 1968-1973.

67. Grosser RJ, Warshawsky D, Vestal JR (1991) Indigenous and enhanced mineralization of pyrene, benzo[a]pyrene, and carbazole in soils. Appl Environ Microbiol 57(12): 3462-3469.

68. Schneider J, Grosser R, Jayasimhulu K, Xue W, Warshawsky D (1996) Degradation of pyrene benz $[\alpha]$ anthracene and benzo[ $\alpha]$ pyrene by Mycobacterium sp. strain RJGII-135, isolated from a former coal gasification site. Appl Environ Microbiol 62(1): 13-19.

69. Ye D, Siddiqi MA, Maccubbin AE, Kumar S, Sikka HC (1996) Degradation of polynuclear aromatic hydrocarbons by Sphingomonas paucimobilis. Environ Sci Technol 30(1): 136-142.

70. Gibson DT, Mahadevan V, Jerina DM, Yogi H, Yeh HJ (1975) Oxidation of the carcinogens benzo[ $\alpha]$ pyrene and benzo[ $\alpha]$ anthracene to dihydrodiols by a bacterium. Science 189(4199): 295-297.

71. Juhasz AL, Stanley GA, Britz ML (2000) Microbial degradation and detoxification of high molecular weight polycyclic aromatic hydrocarbons by Stenotrophomonas maltophilia strain VUN 10,003. Lett Appl Microbiol 30(5): 396-401.

72. Juhasz AL, Stanley GA, Britz ML (2002) Metabolite repression inhibits degradation of benzo[ $\alpha]$ pyrene and dibenz[a,h]anthracene by Stenotrophomonas maltophilia VUN 10,003. J Ind Microbiol Biotechnol 28(2): 88-96.

73. Mahaffey WR, Gibson DT, Cerniglia CE (1988) Bacterial oxidation of chemical carcinogens: formation of polycyclic aromatic acids from benz[ $\alpha]$ anthracene. Appl Environ Microbiol 54(10): 2415-2423.

74. Moody JD, Freeman JP, Fu PP, Cerniglia CE (2004) Degradation of benzo[ $\alpha]$ pyrene by Mycobacterium vanbaalenii PYR-1. Appl Environ Microbiol 70(1): 340-345.

75. Cebron A, Norini MP, Beguiristain T, Leyval C (2008) Real-Time PCR quantification of PAH-ring hydroxylating dioxygenase (PAH-RHD $\alpha$ ) genes from Gram positive and Gram negative bacteria in soil and sediment samples. J Microbiol Methods 73: 148-159.

76. Lozada N, Mercadal JPR, Guerrero LD, Marzio WDD, Ferrero MA, et al. (2008) Novel aromatic ring-hydroxylating dioxygenase genes from coastal marine sediments of Patagonia. BMC Microbiol 8: 50.

77. Rentz JA, Alvarez PJJ, Schnoor JL (2008) Benzo[ $\alpha]$ pyrene degradation by Sphingomonas yanoikuyae JAR02. Environ Pollut 151(3): 669-677.

78. Kweon O, Kim SJ, Jones RC, Freeman JP, Adjei MD, et al. (2007) A polyomic approach to elucidate the fluoranthene-degradative pathway in Mycobacterium vanbaalenii PYR-1. J Bacteriol 189: 4635-4647.

79. Keum YS, Seo JS, Hu Y, Li QX (2005) Degradation pathways of phenanthrene by Sinorhizobium sp. C4. Appl Microbiol Biotechnol 71(6): 935-941.

80. Xia Y, Min H, Rao G, Lv Z, Liu J, et al. (2005) Isolation and characterization of phenanthrene-degrading Sphingomonas paucimobilis strain ZX4. Biodegradation 16: 393-402.

81. Kweon O, Kim SJ, Kim DW, Kim JM, Kim HL, et al. (2014) Pleiotropic and epistatic behavior of a ring-hydroxylating oxygenase system in the polycyclic aromatic hydrocarbon metabolic network from Mycobacterium vanbaalenii PYR-1. J Bacteriol 196(19): 3503-3515.

82. Dyksterhouse SE, Gray JP, Herwig RP, Lara JC, Staley JT (1995) Cycloclasticus pugetii gen. nov., sp. Nov., an aromatic hydrocarbondegrading bacterium from marine sediments. Int J Syst Bacteriol 45(1): 116-123.

83. Wang B, Lai Q, Cui Z, Tan T, Shao Z (2008) A pyrene-degrading consortium from deep-sea sediment of the west pacific and its key member Cycloclasticus sp. P1. Environ Microbiol 10(8): 1948-1963.

84. Gutierrez T, Nichols PD, Whitman WB, Aitken MD (2012) Porticoccus hydrocarbonoclasticus sp. Nov., an aromatic hydrocarbon-degrading bacterium identified in laboratory cultures of marine phytoplankton. Appl Environ Microbiol 78(3): 628-337.

85. Gutierrez T, Whitman WB, Huntemann M, Copeland A, Chen A, et al. (2015) Genome sequence of Porticoccus hydrocarbonoclasticus strain MCTG13d, an obligate polycyclic aromatic hydrocarbon-degrading bacterium associated with marine eukaryotic phytoplankton. Genome Announc 3(3): e00672-e000715.

86. Hedlund BP, Geiselbrecht AD, Bair TJ, Staley JT (1999) Polycyclic aromatic hydrocarbon degradation by a new marine bacterium, Neptunomonas naphthovorans gen. nov., sp. nov. Appl Environ Microbiol 65(1): 251-259.

87. Thompson HF, Lesaulnier C, Pelikan C, Gutierrez T (2018) Visualisation of the obligate hydrocarbonoclastic bacteria Polycyclovorans algicola and Algiphilus aromaticivorans in co-cultures with micro-algae by CARD-FISH. J Microbiol Methods 152: 73-79.

88. Gutierrez T, Green DH, Whitman WB, Nichols PD, Semple KT, et al. (2012) Algiphilus aromaticivorans gen. nov., sp. Nov., an aromatic hydrocarbon- 
degrading bacterium isolated from a culture of the marine dinoflagellate Lingulodinium polyedrum, and proposal of Algiphilaceae fam. nov. Int J Syst Evol Microbiol 62(Pt 11): 2743-2749.

ISSN: 2574-1241

DOI: 10.26717/BJSTR.2020.30.004951

Guang Wu. Biomed J Sci \& Tech Res

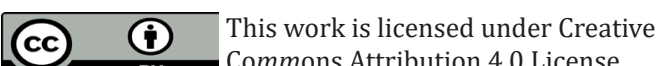

Submission Link: https://biomedres.us/submit-manuscript.php
89. Barnsley EA (1975) The bacterial degradation of fluoranthene and benzo[ $\alpha]$ pyrene. Can J Microbiol 21(7): 1004-1008.

$\begin{array}{ll}\text { BIOMEDICAL } & \text { Assets of Publishing with us } \\ \text { RESEARCHES } & \text { - Global archiving of articles } \\ \text { - Immediate, unrestricted online access } & \text { - Rigorous Peer Review Process } \\ & \text { - Authors Retain Copyrights } \\ \end{array}$

